Article

\title{
Condition Assessment of Power Transformers Based on Health Index Value
}

\author{
Patryk Bohatyrewicz $1,2, * \mathbb{D}$, Janusz Płowucha ${ }^{3}$ and Jan Subocz ${ }^{1,3}$ \\ 1 Faculty of Electrical Engineering, West Pomeranian University of Technology, Sikorskiego 37, \\ 70-313 Szczecin, Poland; jan.subocz@zut.edu.pl \\ 2 Elektrobudowa SA, Porcelanowa 12, 40-246 Katowice, Poland \\ 3 Energo-Complex Ltd., Lotników 9, 41-949 Piekary Śląskie, Poland; Janusz.Plowucha@Energo-Complex.pl \\ * Correspondence: bp19325@zut.edu.pl; Tel.: +48-606-744-307
}

Received: 2 October 2019; Accepted: 11 November 2019; Published: 14 November 2019

check for updates

\begin{abstract}
In electric power systems, health index algorithms are mostly used for evaluation of the transformer population. In this method, some assessment criteria are insensitive when it comes to judging the technical state of the edges of the age spectrum. This paper presents a new health index calculation method that aims to improve the overall effectiveness of the assessment. The proposed algorithm is based on regularly conducted oil diagnostics and easily available maintenance data to enable estimation and updating of the device's health status in short intervals from an operational point of view. This method is compared to another health index algorithm built from the same parameters, but with different weights and an alternative result assessment philosophy. The two health index calculation methods are tested on a population of 96 power transformers and then compared to results obtained with an expert system, which is based on much more advanced diagnostic tests to determine the technical condition of the unit. The results of the experiment show that proper selection of weighting factors of the transformer's technical condition parameters during health index calculation may help in simplifying its assessment while maintaining satisfactory accuracy in comparison to a highly advanced expert method.
\end{abstract}

Keywords: health index; transformers; population analysis; asset management

\section{Introduction}

The operation of transformers is crucial in the context of power system management. Unplanned long-term shutdown of units is a significant expense for transmission network operators. For this reason, the demand for ensuring low failure frequency of transformers is natural. The failure rate is also a subject of regular worldwide research [1].

The operational risk of the transformer is closely related to its technical condition. For its assessment, several methods can be used, which have been explained in a detailed study [2] and in the American Transformer Diagnostics Guide [3]. These techniques can be performed as periodic maintenance or advanced diagnostic procedures or can be implemented in the form of online monitoring systems. Most common techniques, such as oil diagnostics, insulation resistance tests, turns ratio measurements, and inspection of accessories, are performed relatively often and in the state of normal trouble-free operation, with the general technical condition of the transformer being determined on their basis. In the case of transformers with developing defects or aged units, some advanced methods are used to assess their technical condition, such as frequency domain spectroscopy (FDS) and frequency response analysis (FRA) measurements, advanced bushings and on-load tap changer (OLTC) diagnostics, as well as measurement of partial discharges. 
The use of diagnostic procedures is mostly limited to framework operation instructions, which are specific for every country or power system operator. One of these is the American Transformer Maintenance Instruction [4], which indicates time intervals between inspections of various transformer parts and its external equipment.

Due to organizational and financial factors, however, standard assessment of the technical condition is based on periodic tests that are easy to perform. In this case, insulation oil testing is of particular importance and is useful in transformer fault diagnosis [5]. The use of advanced methods usually occurs only in a pre-emergency situation or when making decisions regarding the scope of repair works, which is also connected with predicting units' further operation.

The use of online monitoring of various operation parameters has created a new quality in the current assessment of transformers' technical conditions. However, in line with exploitation experiences, it is recommended that the data obtained from monitoring are generalized to the form of one indicator, usually referred to as the health index. This allows one to synthetically present the technical condition of the transformer in the form of a single numerical indicator, which is more understandable at the level of company management. It also allows a comparison between many transformers with different parameters.

The health index (HI) can be determined based on both a large and relatively small number of specific parameters. This allows for the creation of indicators of varying complexity. At the same time, expert knowledge is required which takes into account such elements as the construction and type of the transformer, principles of operation and service, and the involvement of advanced diagnostic technologies. Health index algorithms take different forms, including the expert systems based on Canadian [6] and Italian [7] experiences, intelligent algorithms using fuzzy logic [8], artificial neural networks [9], and systems based on the mathematical Markov model [10].

In this paper, the authors propose a transformer health index based on the results of advanced oil diagnostics. It is a common and most frequently performed transformer monitoring procedure under the conditions of the Polish power system. The non-complex acquisition of oil samples and the relatively low cost of their physicochemical properties analysis, as well as the increasing popularity of oil online monitoring systems, creates the conditions for ongoing assessment of technical conditions based on the value of the health index. The presented algorithm for determining a health index based on advanced oil diagnostics was tested on a group of 96 power transformers with different exploitation time. The outcome was compared to the results obtained with another health index calculation method and the more advanced TrafoGrade system.

\section{Materials and Methods}

\subsection{Subject of the Experiment}

The subject of research was a group of 96 10-25 MVA transformers working in the Polish $110 \mathrm{kV}$ distribution network. These were transformers with various periods of operation in the power system, from new units to units that had been in operation for 50 years (Figure 1).

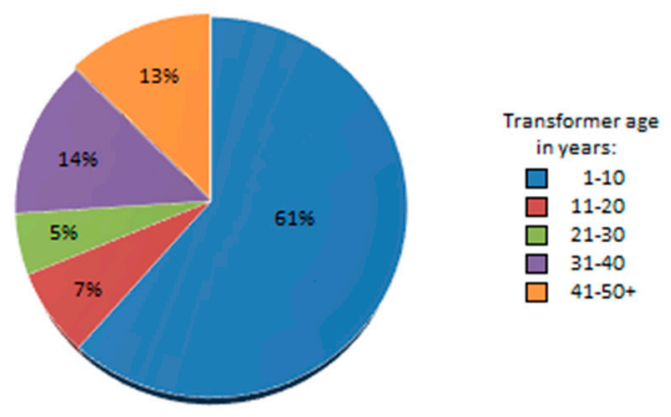

Figure 1. Distribution of tested transformers by the time of operation. 
The transformers in the control group were chosen to minimize the impact of various variables regarding their construction and exploitation. All units were characterized by the same transformer ratio, were equipped with OLTC, and were mostly filled with the same type of mineral oil. The group was located in the same region and controlled by a single operator, so the principles of operation and service were exactly the same for every device.

The values of health indexes for individual transformers were calculated according to the algorithms described in Sections 2.2-2.4 of this paper while using the historical data gathered during maintenance works.

\subsection{Health Index I}

The general principle of creating a health index is that there is a necessity to consider the impact of individual test results on the transformer's technical condition and the development of aging processes. One of these proposals is presented in detail in [11]. The algorithm I contains four categories of parameters, which include the physicochemical properties of the oil ( $\left.\mathrm{HI}_{\mathrm{OIL}}\right)$, the content of gases dissolved in the oil $\left(\mathrm{HI}_{\mathrm{DGA}}\right)$, the condition of solid insulation of windings $\left(\mathrm{HI}_{\mathrm{ISO}}\right)$, and the age and history of the unit's work $\left(\mathrm{HI}_{\mathrm{AGE}}\right)$.

$\mathrm{HI}_{\mathrm{OIL}}$ takes into account the breakdown voltage, water content in oil, acid value, and dielectric dissipation factor. The weight factors and the calculation method are presented in Table 1 and Equation (1), respectively.

$$
\mathrm{HI}_{\mathrm{OIL}}=\sum_{\mathrm{j}=1}^{4} \mathrm{w}_{\mathrm{j}} \cdot \mathrm{F}_{\mathrm{oil}(\mathrm{j})} \text {. }
$$

Table 1. Weighting factors used in the calculation of the physicochemical properties of the oil ( $\left.\mathrm{HI}_{\mathrm{OIL}}\right)$.

\begin{tabular}{cc}
\hline Parameter Value $\left(\mathrm{F}_{\text {oil }(\mathbf{j})}\right)^{\mathbf{1}}$ & Weight $\left(\mathbf{w}_{\mathbf{j}}\right)$ \\
\hline Acidity & 0.2598 \\
Breakdown voltage & 0.1452 \\
Water content & 0.4565 \\
Loss factor & 0.1386
\end{tabular}

${ }^{1}$ Values of $\mathrm{F}_{\mathrm{oil}(\mathrm{j})}$ are based on levels or content of specific parameters and are calculated according to the health index I standards.

The second category includes the results of dissolved gas analysis (DGA), which is a very sensitive indicator of the development of defects in the transformer. The $\mathrm{HI}_{\mathrm{DGA}}$ index includes the content of five gases (Table 2) which are then calculated into a single coefficient using Equation (2).

$$
\mathrm{HI}_{\mathrm{DGA}}=\sum_{\mathrm{j}=1}^{5} \mathrm{w}_{\mathrm{j}} \cdot \mathrm{F}_{\mathrm{j}} .
$$

Table 2. Weighting factors used in the calculation of the content of gases dissolved in the oil ( $\left.\mathrm{HI}_{\mathrm{DGA}}\right)$.

\begin{tabular}{cc}
\hline Gas Content $\left(\mathrm{F}_{\mathbf{j}}\right)^{\mathbf{1}}$ & Weight $\left(\mathbf{w}_{\mathbf{j}}\right)$ \\
\hline Hydrogen $\left(\mathrm{H}_{2}\right)$ & 0.2310 \\
Methane $\left(\mathrm{CH}_{4}\right)$ & 0.2306 \\
Ethane $\left(\mathrm{C}_{2} \mathrm{H}_{6}\right)$ & 0.0772 \\
Ethylene $\left(\mathrm{C}_{2} \mathrm{H}_{4}\right)$ & 0.2301 \\
Acetylene $\left(\mathrm{C}_{2} \mathrm{H}_{2}\right)$ & 0.2312 \\
\hline
\end{tabular}

${ }^{1}$ Values of $\mathrm{F}_{\mathrm{j}}$ are based on content of specific gases and are calculated according to the health index I standards. 
The $\mathrm{HI}_{\mathrm{ISO}}$ index, which characterizes the solid insulation state, takes into account parameters such as the concentration of carbon monoxide and carbon dioxide $\left(\mathrm{F}_{\mathrm{CO}}, \mathrm{F}_{\mathrm{CO} 2}\right)$, their sum $\left(\mathrm{F}_{(\mathrm{CO}+\mathrm{CO} 2)}\right)$, and the content of furfural (2-FAL) compounds ( $\left.\mathrm{C}_{\mathrm{FUR}}\right)$. The $\mathrm{HI}_{\mathrm{ISO}}$ coefficient is calculated based on the following relationship:

$$
\mathrm{HI}_{\mathrm{ISO}}=0.1 \cdot\left(F_{\mathrm{CO}}+F_{\mathrm{CO} 2}+F_{(\mathrm{CO}+\mathrm{CO} 2)}\right)+2.341 \cdot C_{\mathrm{FUR}}^{0.43}
$$

The last category takes into account the transformer's age, work history, and its location. For the sake of this experiment, it was assumed that the expected life of the transformer $\mathrm{T}_{\mathrm{EXP}}$ is 40 years. The initial and final health index values were assumed to be $\mathrm{HI}_{0}=0.3$ and $\mathrm{HI}_{40}=6.5$, respectively.

$$
\mathrm{HI}_{\mathrm{AGE}}=H \mathrm{I}_{0} \cdot e^{0.077 \cdot T}
$$

where $\mathrm{T}$ is the operation time of a transformer in years.

The final health index indicator is calculated based on Equation (5), taking into account the weights given in Table 3. The authors of this algorithm assume that the algorithm ranges in values from 0 to 10, with the criteria for assessing its results given in Table 4 .

$$
\mathrm{HI}=\sum_{\mathrm{j}=1}^{4} \mathrm{k}_{\mathrm{j}} \cdot \mathrm{HI}_{\mathrm{j}}
$$

Table 3. Weighting factors used in the calculation of the final health index I value. Legend: $\mathrm{HI}_{\mathrm{ISO}}$, the condition of solid insulation of windings; $\mathrm{HI}_{\mathrm{AGE}}$, the age and history of the unit's work.

\begin{tabular}{cc}
\hline Category $\left(\mathbf{H I}_{\mathbf{j}}\right)$ & Weight $\left(\mathbf{k}_{\mathbf{j}}\right)$ \\
\hline $\mathrm{HI}_{\mathrm{OIL}}$ & 0.0699 \\
$\mathrm{HI}_{\mathrm{DGA}}$ & 0.0946 \\
$\mathrm{HI}_{\mathrm{ISO}}$ & 0.2661 \\
$\mathrm{HI}_{\text {AGE }}$ & 0.5695 \\
\hline
\end{tabular}

Table 4. Assessment criteria for judging a transformer's technical state based on the health index I value.

\begin{tabular}{cc}
\hline Health Index Value & Technical State \\
\hline $0-3.5$ & Good \\
$3.5-5.5$ & Average \\
$5.5-7.0$ & Bad \\
$7.0-10$ & Risky \\
\hline
\end{tabular}

However, the aforementioned assessment criteria (Table 4) are not compatible with the range of available solutions obtained with this algorithm. The proposed judgement standards are graphically represented in Figure 2a. To further evaluate those criteria, the authors have carried out simulations to obtain the range of possible solutions for the studied population (Figure $2 b$ ).

The discrepancy presented in Figure 2a,b has two critical points. The first concerns transformers at a very young age, which may be inaccurately assessed because algorithm I rates nearly every unit of up to 10 years of operation as in good technical condition regardless of its actual health index score. This is an extremely unfavorable situation because younger units with developing defects may be neglected in the case of population analysis. The second point concerns transformers which have exceeded their expected operation time. Some of these, still in relatively good technical state considering their age, could be wrongly classified as risky in the context of further operation and could be put out of service. These two points show a major flaw in the rigid boundary assessment system for a health index I value, 
as in the case of a few probable unsuccessful decisions it may have an unnecessary direct economic effect on transformer population management.

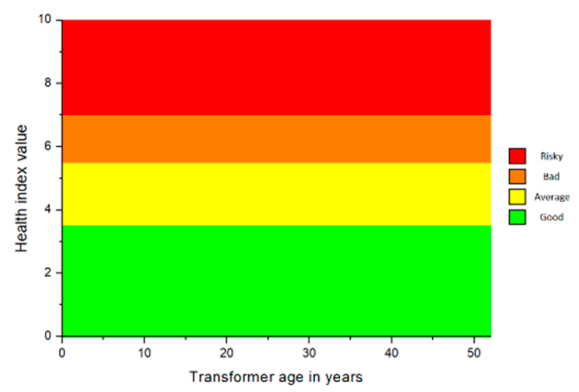

(a)

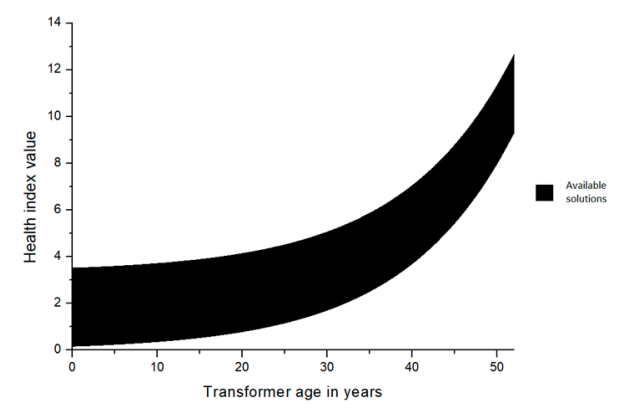

(b)

Figure 2. Range of values available for algorithm I for the age span of the analyzed population: (a) according to the authors of the algorithm; (b) real values available to the algorithm.

\subsection{The TrafoGrade System}

The TrafoGrade [12] is a system used for comprehensive assessment of the technical condition of transformers developed and used by Energo-Complex Ltd. (Piekary Ślaskie, Poland) to support decisions regarding operation prospects and renovation planning. For this reason, it takes into account the importance of the transformer in the power system when selecting the operation strategy.

Figure 3 shows a diagram of the main algorithm of the TrafoGrade system which is used for the assessment of the transformer's technical condition. The assessment takes into account three main groups of parameters. Group I contains basic tests, such as inspection of accessories, on-load tap changer, and overall external examination. In group II, operational tests of the active part of the transformer are taken into account, which include insulation and winding resistance measurements, oil diagnostics (breakdown voltage and DGA) as well as combined sweep frequency response analysis (SFRA) and mechanical vibration (VM) measurements [13]. Group III is the basis for planning renovations and forecasting the further life of the unit. It takes into account the physicochemical properties of the oil (acidity and loss factor), moisture in paper-oil insulation, furan compound content, and the transformer's age. It was assumed that exceeding the permissible values by any parameter included in group I or II would result in a negative assessment of the technical condition and exclusion of the transformer from further operation. This means that the TrafoGrade system only classifies devices whose operation does not involve a high current operational risk.

The second part of the algorithm predicts the importance of the transformer in the power grid based on its operating parameters, location in the power system, the technical possibility of replacing the transformer, and the redundancy during a failure or other adverse events. Using the results obtained in the first part, it is possible to determine the recommended operation regime of the tested transformer (Figure 4). The operating levels are divided into simplified (U), normal (N), and special (S). The first group (U) consists of units in good technical condition and relatively low importance. Conversely, transformers with special operation (S) are characterized by poor technical condition or high significance in the context of energy system reliability.

The final result of the technical condition assessment using the TrafoGrade system is the development of individual perspectives for the operation of the tested device. This information is particularly important from the perspective of persons managing transformer fleet operation, as it facilitates the implementation of a reliable diagnostic and repair plan over the next few years. 


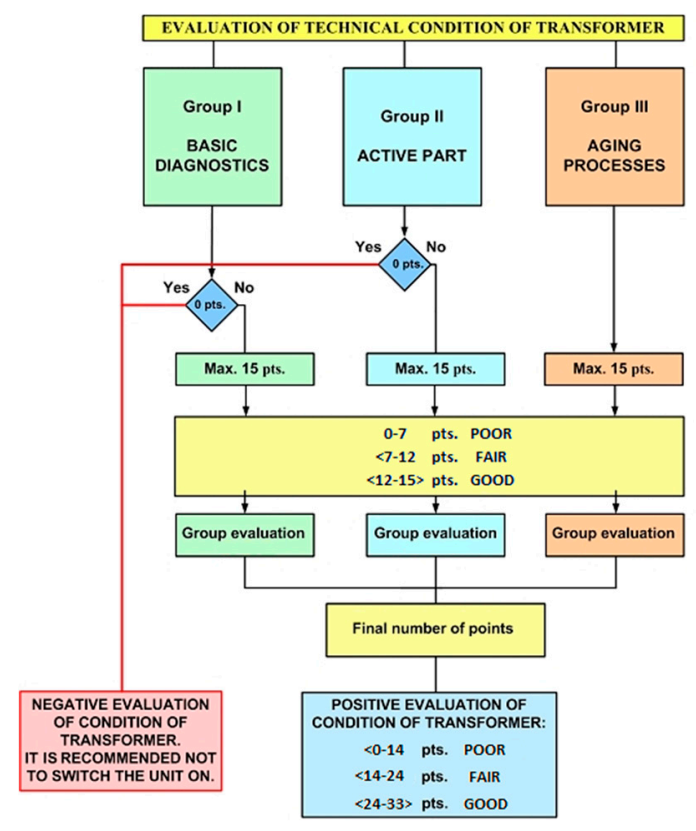

Figure 3. Algorithm for determining the technical condition of the transformer in the TrafoGrade system.

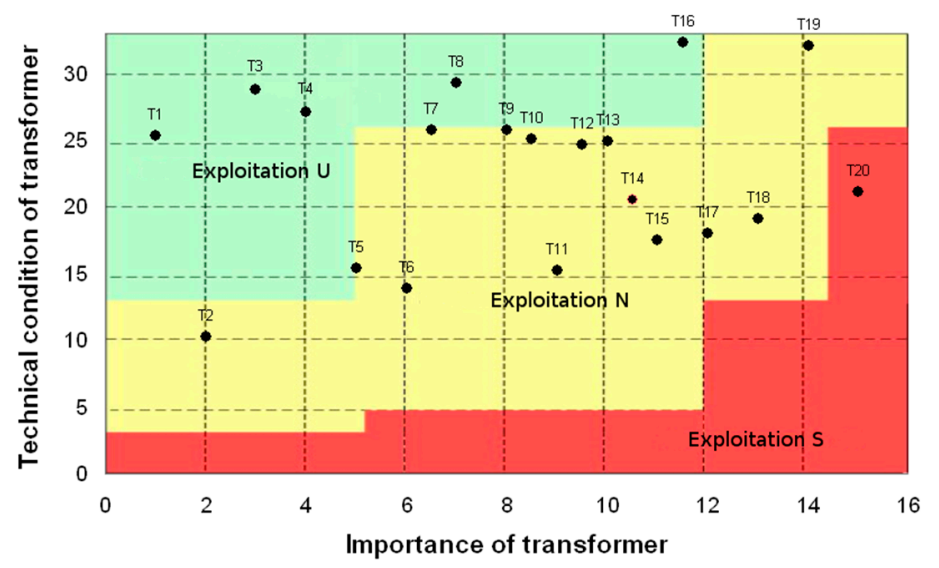

Figure 4. Analysis of an exemplary population of transformers using the TrafoGrade system.

\subsection{Health Index II}

The algorithm of technical condition assessment proposed by the authors of the article is based solely on advanced oil diagnostics. Its main assumption is the ability to quickly and reliably evaluate based on uncomplicated acquisition of analytical data from offline or online systems. The foundation for the construction of this algorithm is similar to the one described in Section 2.2; however, the weighting factors of oil properties, which are presented in Table 5, are different.

Critical levels of the mentioned parameters described in the operating instructions in the Polish power system were adopted as the reference point [14]. On the one hand, these values take into account the requirements of the International Electrotechnical Commission (IEC) standard [15], and on the other hand, results from many years of practical experience in the Polish national grids are taken into account. This indicates that the influence of some properties on the development of defects in the active part of the transformer and its technical condition is greater, while for others it is smaller. For this reason, a much greater impact factor on the final score was attributed to such gases as hydrogen, acetylene, and furfural compounds. On the other hand, oil properties such as water content and breakdown voltage have little effect. It was also assumed that transformer operation time is of great importance because based on oil tests, the possibility of short-circuit strength assessment is incomplete. 
However, for a comprehensive assessment of the technical condition, it is necessary to determine possible deformations and loosening of the windings. This is additionally possible using combined SFRA and VM on-site tests [16], which are only included in the more advanced TrafoGrade system.

Table 5. Components and weighting factors used to calculate the health index (HI) based on advanced oil diagnostics.

\begin{tabular}{ccc}
\hline Category & Parameter & Weight \\
\hline \multirow{3}{*}{ Physicochemical properties } & Acidity & 0.0776 \\
& Loss factor & 0.0573 \\
& Water content & 0.0241 \\
& Breakdown voltage & 0.0258 \\
\hline & Hydrogen $\left(\mathrm{H}_{2}\right)$ & 0.1042 \\
& Methane $\left(\mathrm{CH}_{4}\right)$ & 0.0488 \\
Dissolved gas analysis & Ethane $\left(\mathrm{C}_{2} \mathrm{H}_{6}\right)$ & 0.0163 \\
& Ethylene $\left(\mathrm{C}_{2} \mathrm{H}_{4}\right)$ & 0.0488 \\
& Acetylene $\left(\mathrm{C}_{2} \mathrm{H}_{2}\right)$ & 0.1074 \\
\hline \multirow{3}{*}{ Cellulose aging } & Carbon oxide $(\mathrm{CO})$ & 0.0471 \\
& Carbon dioxide $\left(\mathrm{CO} \mathrm{O}_{2}\right)$ & 0.0471 \\
& Furans $(2-\mathrm{FAL})$ & 0.2199 \\
\hline \multirow{2}{*}{ Age coefficient } & Age & \\
& Transformer load & 0.1756 \\
& Operation history \\
\hline
\end{tabular}

The developed algorithm for determining the health index contains numerical values mainly in the range of 0 to 10 points. These were divided into basic three zones marked as good, average, and risky (Figure 5a). This algorithm is not based on rigid boundaries when it comes to technical state assessment but is rather based on the percentage value of a possible range of solutions (Figure 5b). Table 6 presents the criteria for the assessment of the technical condition according to the developed algorithm.

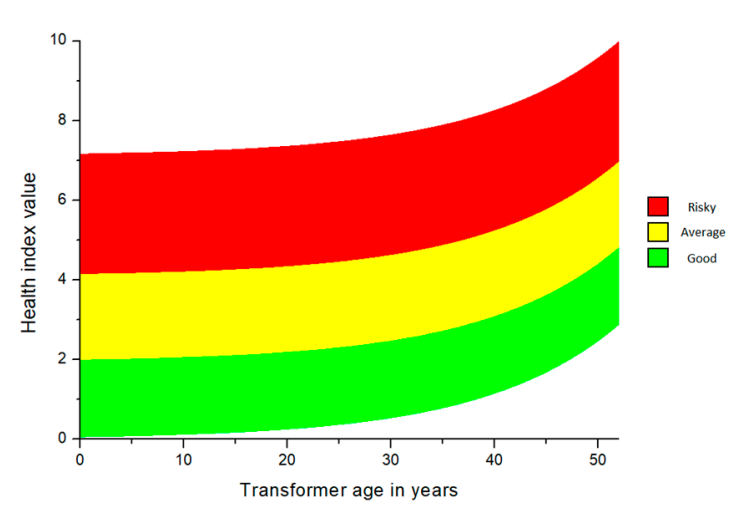

(a)

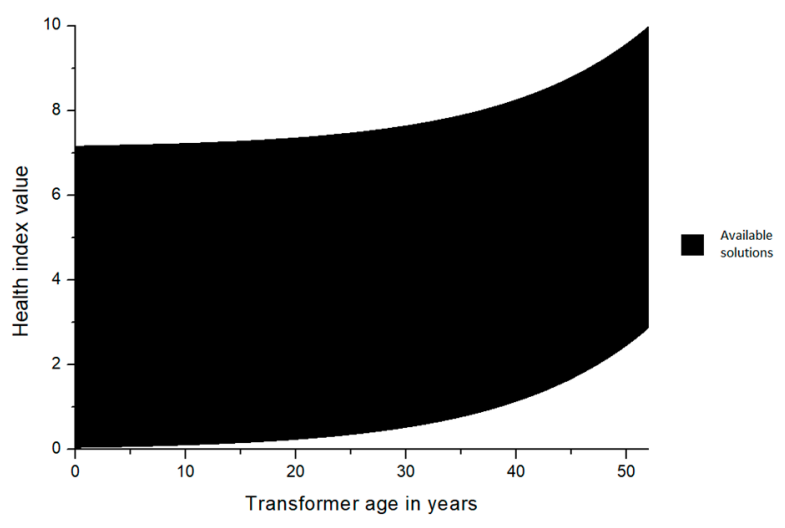

(b)

Figure 5. Criteria for assessing the technical condition depending on the HI value of the proposed algorithm: (a) graphic representation; (b) range of possible solutions.

Table 6. Criteria for technical condition assessment based on health index values for the proposed algorithm.

\begin{tabular}{cc}
\hline Health Index Value & Technical State \\
\hline $0-27 \%$ & Good \\
$27-57 \%$ & Average \\
$57-100 \%$ & Risky \\
\hline
\end{tabular}




\section{Results}

Figure 6 represents the health index values of a group of 96 transformers which were calculated based on algorithm I (Figure 6a) and according to the advanced oil diagnostics algorithm II (Figure 6b). Both figures show that with increasing time of operation the value of $\mathrm{HI}$ increases naturally. However, in the case of health index I, much higher growth is observable. For this method, the decisive factor is exploitation time rather than the technical state of the transformer. This leads to a situation in which most units that have been in operation for over 40 years are marked as bad or risky in terms of their future.

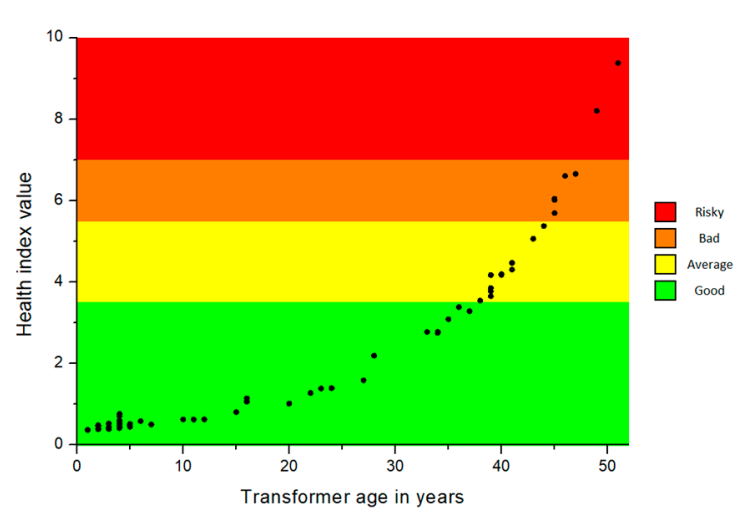

(a)

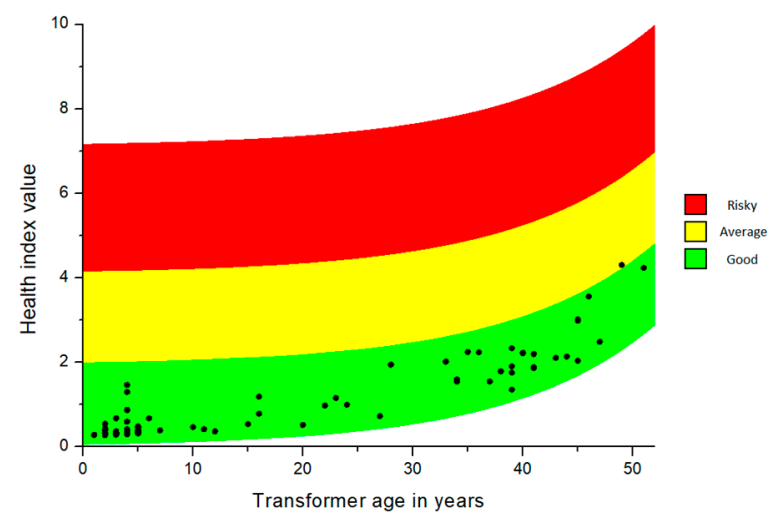

(b)

Figure 6. Values of health indexes of 96 transformers: (a) according to algorithm I; (b) based on the advanced oil diagnostics algorithm II.

However, according to the advanced oil diagnostics method, the operation of 96 transformers was assessed as being free of excessive risk (Figure 6b). Despite this, quite large differences in health index values can be observed in particular age groups. For example, the HI score of some transformers after 5-15 years of operation may be comparable with the values achieved by devices that have already been working for 30-40 years. Undoubtedly, this is related to the type of load and the place of installation in the power system. It was found that transformers with an increased health index value work with an average load of $0.6 \div 0.7 \cdots S_{n}$, which is also characterized by large momentary overloads.

The studied population was also assessed using the TrafoGrade system. To summarize all results, a matrix was built containing all technical condition decisions obtained with three methods (Table 7). To organize everything into a three-point rating scale, the results obtained with algorithm I which were marked as average and bad were merged into the average category.

Table 7. The results of transformer population analysis using three different algorithms.

\begin{tabular}{cccc}
\hline Technical Condition Judgement & Health Index I & Health Index II & TrafoGrade System Classification \\
\hline Good & 78 & 95 & 94 \\
Average & 16 & 1 & 2 \\
Risky & 2 & 0 & 0 \\
\hline
\end{tabular}

\section{Discussion}

Since the TrafoGrade system is the most complex algorithm and incorporates much more data than the other two methods, it is assumed that it also provides the most reliable output for technical condition judgement. This means that the whole population of 96 transformers is free of excessive risk in further operation and only two units are in average condition.

The health index I calculation method showed significantly different outcomes compared to the TrafoGrade method. This is due to the extended time of operation for some units, as they had already 
exceeded their predicted lifetime. The higher value of the age coefficient leads to the evaluation of older units as unable to undergo further operation. Nonetheless, operational and internal revision experiences [17] show that, depending on the quality of service, the technical condition of the active part of such a transformer is satisfactory considering their age, and after a minor renovation their operation period can be extended by another 10-15 years [18]. In a similar study [19], in an analyzed group of twelve fifty-year-old transformers, all of the transformers were ranked as bad or risky during the five years of the experiment, but none of them ended their lives despite the critical evaluation obtained with algorithm I.

The method proposed by authors based on advanced oil diagnostics ranked almost all transformers as in good technical condition. This algorithm prefers the presence of such gases as hydrogen and acetylene and the presence of furfural. These are compounds generated mainly during the development of defects, thermal aging of the insulation, and the aging changes in the active part of the transformers. However, the algorithm takes into account the service life factor to a much lesser extent compared to health index I, which is possible under the conditions of good current service. This is also intended to allow more accurate observation of changes in health index value over time, as this increases the impact of the current technical condition on the final result.

The comparison of Figure $6 \mathrm{~b}$ and Table 7 indicates that the assessment of the technical condition in the TrafoGrade system was practically consistent with the conclusions drawn with the HI values determined with algorithm II. This correlation seems promising in terms of future work on effective simplification of transformer technical condition assessment based on the analysis of only selected oil and operation parameters. However, it should be remembered that the TrafoGrade system uses expert knowledge to a much greater extent because it also includes such parameters as analysis of deformation and loosening of the windings, quality of bushings insulation, and operation of the OLTC. It should also be noted that the TrafoGrade system demands the transformer to be de-energized for several hours, which usually requires a change in the configuration of the power grid and is both time-consuming and expensive.

Some differences in the values of the health index for individual units were also observed. In the group of transformers operating for less than 5 years, it was found that some of them were in worse condition compared to others. On the other hand, the condition of some transformers operating for 35-40 years was comparable to units of devices working 15-25 years. This effect, according to the authors, was caused by three main factors:

- The quality of service

- Average annual transformer load

- The place of installation in the power system

The algorithms used to calculate health index values and their criterion values should take into account the requirements of IEC standards, local transformer maintenance instructions, and expert knowledge supported by many years of experience in transformer operation. The main problem is the choice of parameters forming a health index and determining the coefficients of the impact of individual parameters on the total value. This is an arbitrary choice and depends, among other factors, on many years of experience in transformer operation in the power grid. For these reasons, depending on the type of selected parameters and adopted values of influence coefficients, as well as critical descriptors, the health index may characterize a transformer's technical condition in different ways. Hence, HI determination algorithms should be verified by experts on a large group of transformers working in a given power system.

\section{Conclusions}

Presentation of the technical condition of transformers in the form of a health index is being more and more often used as a tool supporting supervision services in managing and servicing fleets of 
power transformers. It allows for preliminary planning of shutdown time, the scope of repairs, and when to choose the operation strategy.

The algorithm used to determine transformers' health index developed by the authors uses the results of advanced transformer oil diagnostics, which can be easily obtained in online or offline measurements without having to put the transformer out of operation. This allows users to update the health index value at any given time, which is very convenient compared to conventional methods used in transformer diagnostics and the whole process of population data management.

The proposed algorithm has been shown to produce more accurate results than health index I when compared to the highly advanced TrafoGrade system. The reduction of the weight of the age factor increases the importance of the current technical condition of the transformer in its overall assessment, which leads to the correct assessment of individual units in advanced age. Furthermore, assigning appropriate weights to the analyzed parameters included in the health index allows the user to observe deviations from population averages, which helps in identifying potentially problematic transformers regardless of their age.

Effective simplification of transformer health evaluation is promising in terms of cost optimization of transformer fleet management. This process is vital, as early fault detection and handling is crucial to extending transformers' operation period. Transformers are the most costly devices in power substations and the development of algorithms such as the health index is necessary to maximize the economic efficiency of grid operators in the future.

Author Contributions: Conceptualization, P.B.; methodology, P.B., J.P., and J.S.; investigation, P.B. and J.P.; resources, J.P.; supervision, J.S.; visualization, P.B.; writing-original draft preparation, P.B., J.P., and J.S.; writing-review and editing, P.B., J.P., and J.S.

Funding: This research received no external funding.

Conflicts of Interest: The authors declare no conflict of interest.

\section{References}

1. Tenbohlen, S.; Jagers, J.; Vahidi, F.; Müller, P.; Lapworth, J.; Yukiyasu, S.; Desai, B.; McIntosh, A.; Bastos, G.; Bo, L. Transformer Realiability Survey; Technical Brochure 642; CIGRE: Paris, France, 2015.

2. Tenbohlen, S.; Coenen, S.; Djamali, M.; Müller, A.; Samimi, M.H.; Siegel, M. Diagnostic Measurements for Power Transformers. Energies 2016, 9, 347. [CrossRef]

3. United States Bureau of Reclamation. Facilities Instructions, Standards and Techniques, Volume 3-31. In Transformer Diagnostics; United States Bureau of Reclamation: Denver, CO, USA, 2003.

4. United States Bureau of Reclamation. Facilities Instructions, Standards and Techniques, Volume 3-30. In Transformer Maintenance; United States Bureau of Reclamation: Denver, CO, USA, 2000.

5. Nicola, C.I.; Nicola, M.; Nitu, M.C.; Aciu, A.M. Fuzzy Logic System Based on Dissolved Gas Analysis and Furan Analysis for Power Transformer Fault Diagnosis. UPB Sci. Bull. Ser. C 2019, 81, 183-196.

6. Jahromi, A.N.; Piercy, R.; Cress, S.; Service, J.R.R.; Fan, W. An Approach to Power Transformer Asset Management Using Health Index. IEEE Electr. Insul. Mag. 2009, 25, 20-34. [CrossRef]

7. Scatiggio, F.; Pompili, M.; Calacara, L. Transformers Fleet Management Through the Use of an Advanced Health Index. In Proceedings of the 2018 Electrical Insulation Conference (EIC), San Antonio, TX, USA, 17-20 June 2018. [CrossRef]

8. Abu-Elanien, A.E.B.; Salama, M.M.A.; Ibrahim, M. Calculation of a Health Index for Oil-Immersed Transformers Rated Under 69 kV Using Fuzzy Logic. IEEE Trans. Power Deliv. 2012, 27, 2029-2036. [CrossRef]

9. Abu-Elanien, A.E.B.; Salama, M.M.A.; Ibrahim, M. Determination of transformer health condition using artificial neural networks. In Proceedings of the 2011 International Symposium on Innovations in Intelligent Systems and Applications, Istanbul, Turkey, 15-18 June 2011. [CrossRef]

10. Yahaya, M.S.; Azis, N.; Ab Kadir, M.Z.A.; Jasni, J.; Hairi, M.H.; Talib, M.A. Estimation of Transformers Health Index based on the Markov Chain. Energies 2017, 10, 1824. [CrossRef] 
11. Li, E.; Song, B. Transformer Health Status Evaluation Model Based on Multi-feature Factors. In Proceedings of the 2014 International Conference on Power System Technology (POWERCON 2014), Chengdu, China, 20-22 October 2014. [CrossRef]

12. Transformers Technical Condition Assessment and Population Management (In Polish-Ocena Stanu Technicznego I Zarządzanie Populacja Transformatorów); OBRE; Joint Publication: Piekary Śląkie, Poland, 2013; ISBN 978-83-938292-0-0.

13. Kornatowski, E.; Banaszak, S. Diagnostics of a Transformer's Active Part with Complementary FRA and VM Measurements. IEEE Trans. Power Deliv. 2014, 29, 1398-1406. [CrossRef]

14. Framework Instructions for Transformer Operation (in Polish-Ramowa Instrukcja Eksploatacji Transformatorów); ZPBE ENERGOPOMIAR-ELEKTRYKA; Joint Publication: Gliwice, Poland, 2012; ISBN 978-83-916040-4-5.

15. IEC Standard. Mineral Oil-Filled Electrical Equipment in Service-Guidance on The Interpretation of Dissolved and Free Gases Analysis; 60599; IEC Standard: Geneve, Switzerland, 2015.

16. Banaszak, S.; Kornatowski, E. Evaluation of FRA and VM Measurements Complementarity in the Field Conditions. IEEE Trans. Power Deliv. 2016, 31, 2123-2130. [CrossRef]

17. Malewski, R.; Szrot, M.; Płowucha, J. Detection of Transformer Winding Deformation using Frequency Response Analysis and Evaluation of Results. Energetyka 2004, 6, 341-345.

18. Malewski, R.; Subocz, J.; Szrot, M.; Płowucha, J.; Zalewski, R. Condition Assessment of Medium-Power Transformers using Diagnostic Methods: PDC, FDS, FRA to Support Decision to Modernize or Replace Service-Aged Units. In Proceedings of the Session CIGRE 2008, Paris, France, 24-29 August 2008.

19. Ortiz, F.; Fernandez, I.; Ortiz, A.; Renedo, C.J.; Delgado, F.; Fernandez, C. Health Indexes for power transformers: A case study. IEEE Electr. Insul. Mag. 2016, 32, 7-17. [CrossRef]

(C) 2019 by the authors. Licensee MDPI, Basel, Switzerland. This article is an open access article distributed under the terms and conditions of the Creative Commons Attribution (CC BY) license (http://creativecommons.org/licenses/by/4.0/). 